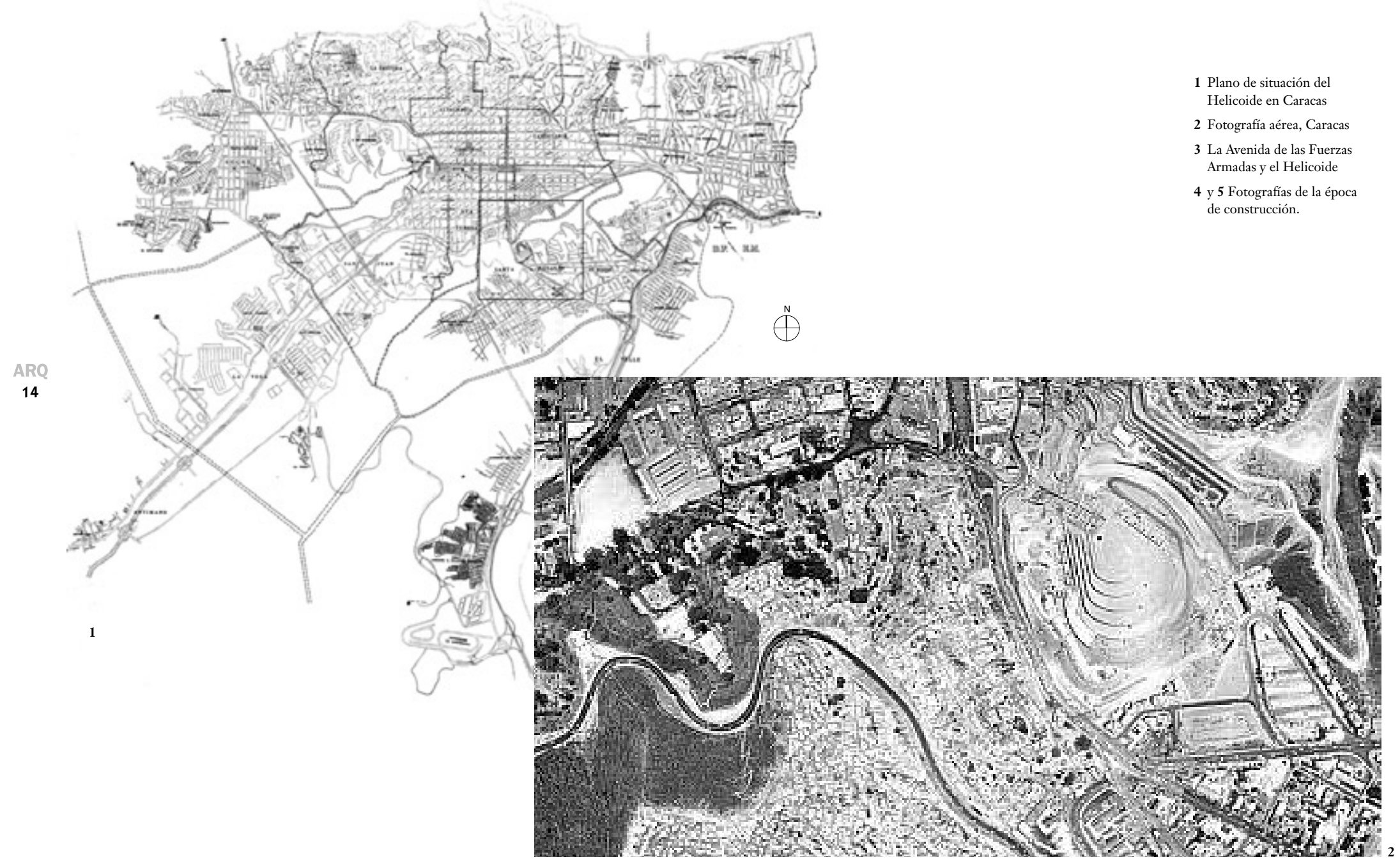

José Rosas, Iván González

\title{
El Helicoide de Caracas
}

Durante las décadas del '50 y '60 se desarrolló en Caracas un importante número de obras de arquitectura y urbanismo, que ilustran -con su carácter fragmentariola realidad concreta de los proyectos modernos.

En este caso, la figura de un belicoide asentada sobre una colina, como un manto de doble espiral, en uno de los centros más densos de la ciudad. Es un edificio para ser recorrido, una apología al uso del automóvil en los tempranos años sesenta; pero a pesar de esa aparente rigidez ba sido utilizado indistintamente como centro comercial y como cuartel de policía.

Palabras clave: Arquitectura moderna, Caracas, centros comerciales, centros de exposiciones.

During the 1950s and 1960s, in Caracas, a significant number of architecture and urbanism projects were developed. Their fragmentary nature illustrates the concrete reality of modern projects.

In this case, a belicoidal shape stands on a bill, as a double spiral mantle, in one of the city's denser centers. It is a building meant to be traversed, an apology of the use of cars in the early seventies. In spite of its apparently rigid character, however, it has indistinctly served as a police headquarters and as a commercial center.
Caracas, a partir de $1936^{2}$, registra una profunda mutación en su estructura urbana, abandonando no sólo el lugar y el derrotero colonial que desde el siglo XVI constituyó la lógica de sus desarrollos, sino invalidando todos los sistemas de articulación y construcción urbana previamente establecidos.

En 1952 la introducción del vehículo en Caracas generó fuertes acciones de modernización. A partir de ello se originan iniciativas destinadas a ampliar, mediante ensanches, distintas calles, construir nuevas avenidas, mejorar y pavimentar vías y, sobre todo, proponer vías rápidas urbanas para los nuevos medios de transporte.

Cabe reconocer que en Caracas se despliega una manera de superar las dificultades topográficas que presentaba el Valle ${ }^{3}$, pero también un punto de partida para delinear una estrategia de urbanización sustanciada en factores de eficiencia y funcionalidad, requerimientos de amplios espacios que necesita la nueva etapa petrolera y garantizar la escala territorial de las nuevas intervenciones.

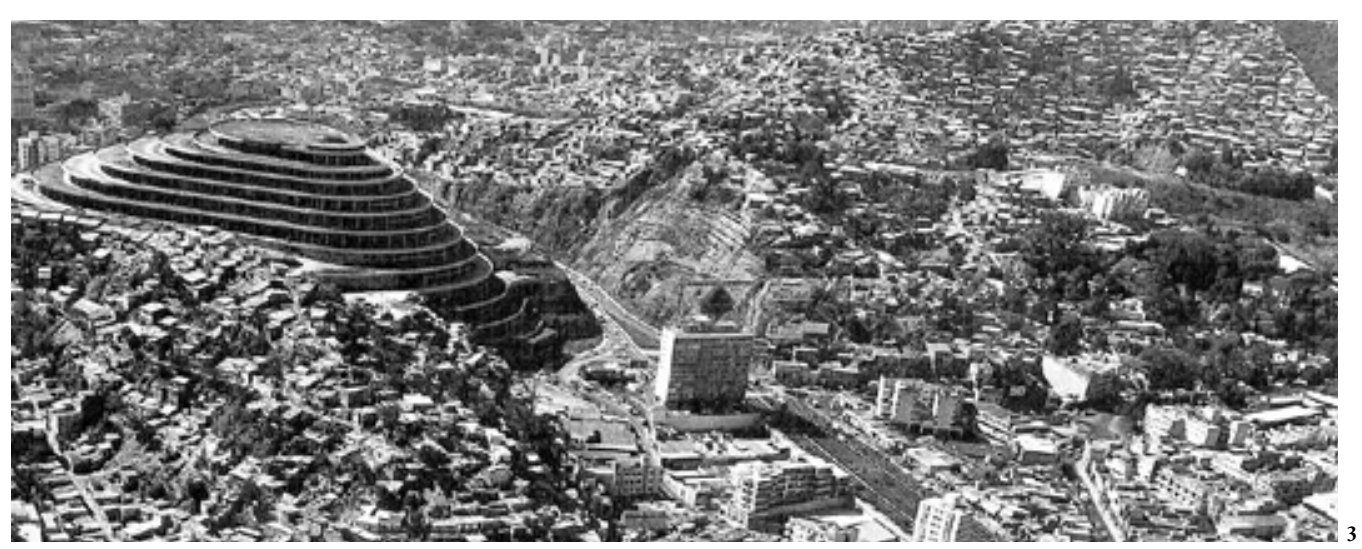




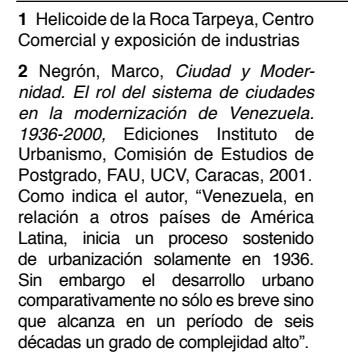

3 Morales Tucker, Alberto; Valery, Caracas. Evolución del patrón urban desde la fundación de la ciudad has el período petrolero. 1567-1936. cado hacia el norte por una alta cenma de montañas y una serie de cerros $y$ colinas más bajos por los otros puntos cardinales. La porción mayor del valle es un espacio bastante plano, de form en dirección estecordillera, y que tiene unos $18 \mathrm{~km}$ de largo por 3,5 de ancho. Esta porción, bautizada Valle de San Francisco, tien unos apéndices igualmente planos que
se orientan del noreste al suroeste $y$ se se orientan del noreste al suroeste y se
desprenden del valle principal cerca de su punto medio".
4 Le Corbusier, Hacia una arquitec
tura Editorial Poseidón, Buenos Aires, tura, Editorial Poseidón, Buenos Airesa
1977 , segunda edición. Primera española, Barcelona, España Yare" Corbusier en "Vers une Architectrasat'́nticos como las imágenes de Lamoriciére, o el Empress of Asia, los aviones como el Air Express que cubria la ruta Paris-Londres en dos horas y los automóviles Humbert 1907, cuestiones fundamental y su impacto en los aspectos de movilidad y dentro de la organización

5 Vegas, Federico; González Viso,
Iván, Venezuela siglo XX: visiones y
testimonios, Fundación Polar, Caracas,
diciember de 2000 . Como señala el
autor en el ensayo "Caracas una
ciudad en sus redes y en sus tramas",
el papel principal en la difusión de
los postulados de la ciudad moderna
estará encargado a un conjunto de
obrasmonumentales que sedesarrollan
de manera independiente en el nuevo
espacio urbano y naturalmente sin
ninguna relación con el centro histórico
fundacional de Caracas. Las nuevas
instancias funcionales son satisfechas

por el Centro Simón Bolívar o ciudad financiera (obra de Cipriano Domínguez), el 23 de enero o la Ciudad habitacional obrera y la Ciudad Universitaria (obras de Carlos Raúl
Villanueva), el Círculo Militar, la Academia Militar y el Paseo de los Próceres como la ciudad militar (obras de Luis Malaussena), el Hipódromo La Rinconada (obra de Arthur Froelich) y la Ciudad Vacacional de Caracas Como la ciudad del esparcimiento, y el ciudad comercial.
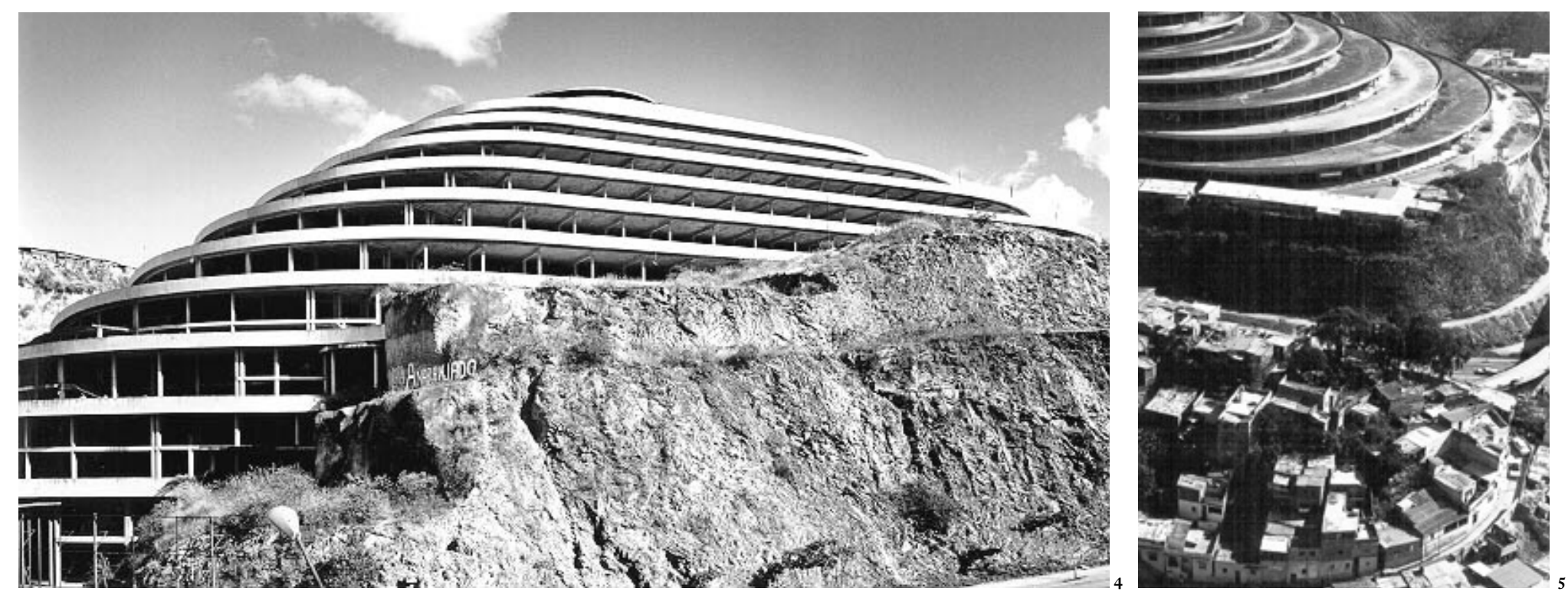

La visión de una nueva ciudad en la Caracas de los '50, extendida y engrandecida por complejos sistemas de circulación basados en un protagonismo del uso de vehículos privados y los desplazamientos separados según los distintos tipos de tráfico, serán en definitiva las variables organizadoras de las áreas de desarrollo potencial y el recurso reiterativo para cualquier nuevo desarrollo. Por otra parte, a través de estas premisas urbanas se consolida una representación urbana en consonancia con la idea maquinista que Le Corbusier preconizaba de la ciudad moderna ${ }^{4}$, en especial aquella vinculada a la segregación de las distintas formas de transporte y sus interconexiones.

El Plan Vial generó una nueva forma de lectura y organización del territorio, y el protagonismo del automóvil pasa a ser el elemento clave del crecimiento y localización de nuevas actividades en Caracas. Cabe recordar que en 1948 Robert Moses, creador de muchas de las vías expresas neoyorquinas (entre las que destaca la propuesta para la East River Drive) es traído para realizar un reporte para un jerarquizado sistema de circulación urbano e intraurbano.

La nueva planificación fomentará la circulación de vehículos, entendidas todas las gamas de formas de transporte y velocidades, siendo elevadas las autopistas en este nuevo territorio de ciudad a la categoría de edificio, en que la rapidez es signo y valor esencial de la modernidad. Al mismo tiempo, y en correspondencia con este tejido fibroso de superficies de desplazamientos, emerge un conjunto de paquetes urbanos de escala monumental, cuyos conjuntos arquitectónicos basados en la especialización funcional y en la autonomía de dichos enclaves ${ }^{5}$, legitiman al estacionamiento como espacio público.

Situados estratégicamente en esta nueva dimensión de ciudad, y relacionadas entre ellas por medio del sistema de movimiento, emergerá el Helicoide de la Roca Tarpeya.

Ideado como un Centro Comercial y Exposición de Industrias ${ }^{6}$, las conexiones con las infraestructuras serán uno de los temas prioritarios que el proyecto ha de resolver.

Ubicado en el punto de conjunción de los sectores más densos de la ciudad y en el área mejor servida por el sistema de vialidad del Área Metropolitana, el Helicoide es una forma geométrica triangular que resulta de la forma piramidal de la colina que constituye su base. La edificación consiste en un manto helicoidal de doble espiral, cuyas rampas entrelazadas envuelven a la colina, como aceras aéreas en una pendiente muy suave $(2,5 \%$ en promedio) a lo largo de las cuales se localizan locales comerciales, cuyos módulos permiten integración horizontal o vertical. La altura de los locales es ajustada a medida que se asciende, de modo de conservar una pendiente uniforme.

En efecto, con la doble espiral se posibilita que el techo de los locales de la espiral ascendente sea el estacionamiento de la espiral descendente y así sucesivamente hasta comprender seis rampas en total, con un recorrido de cuatro kilómetros y una superficie de exhibición de tres kilómetros. Además, las aceras de peatones están protegidas por la vialidad superior construida en volado. Paralelo al sistema de movimiento vehicular y sus respectivos estacionamientos, la circulación peatonal sigue el mismo recorrido de la espiral, en este caso por la parte interior y se complementa con cuatro núcleos de circulación vertical y escaleras mecánicas. En tal sentido este proyecto permite el manejo de velocidades que abarcan desde el peatón hasta las del tráfico urbano de los perímetros, intentando que las discordancias de las diferentes formas de movimiento sean su programa. De hecho, inmediato a la penetración del edificio y al nivel de la primera rampa se localiza el Centro 

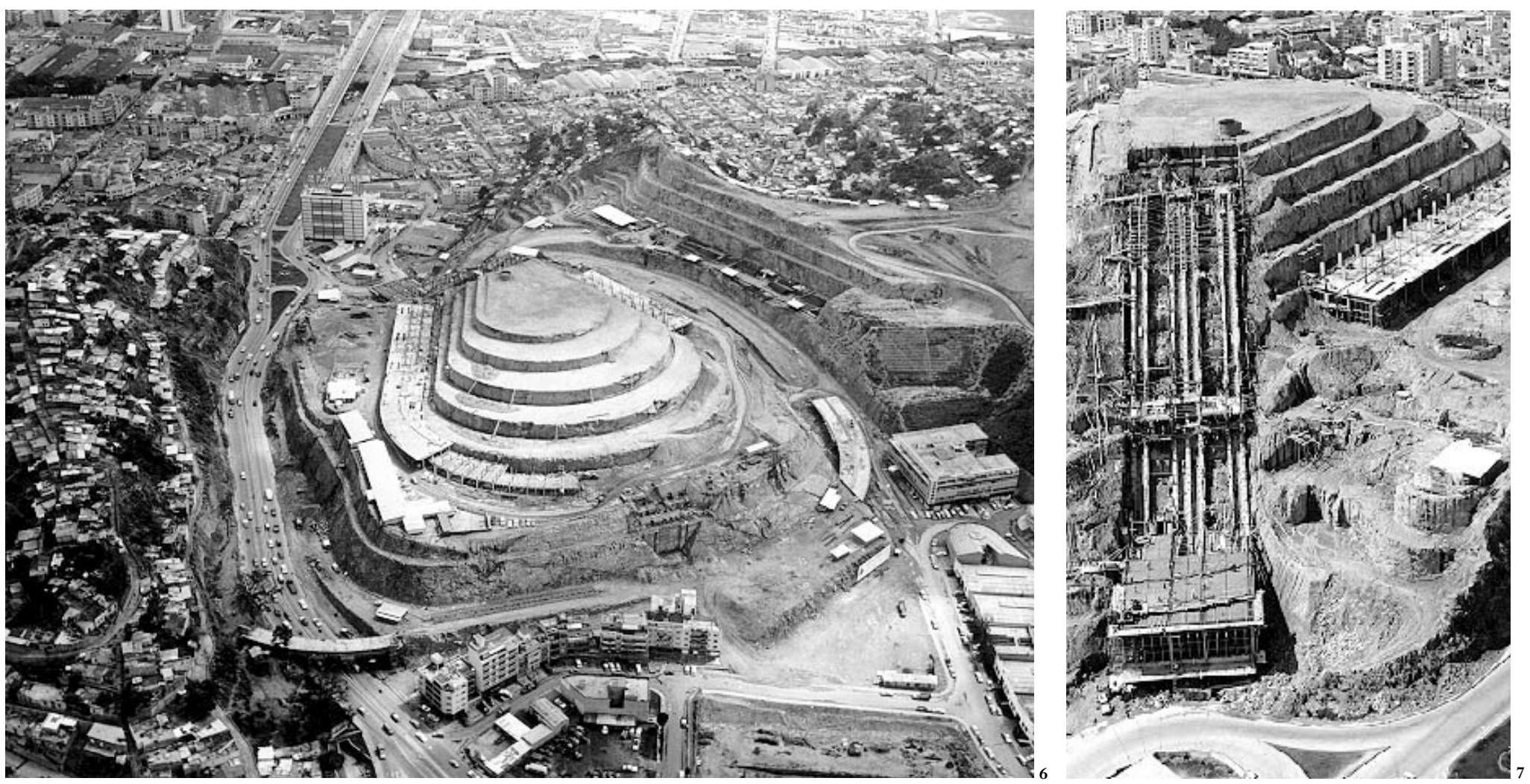

6, 7,8 y 9 Fotografías de la

época de construcción.

Modelación de la Roca

Tarpeya, y construcción d

la envolvente de rampas

10 y 11 Maqueta del proyecto

original

$12 \mathrm{El}$ equipo de arquitectos en

el estudio, 1958
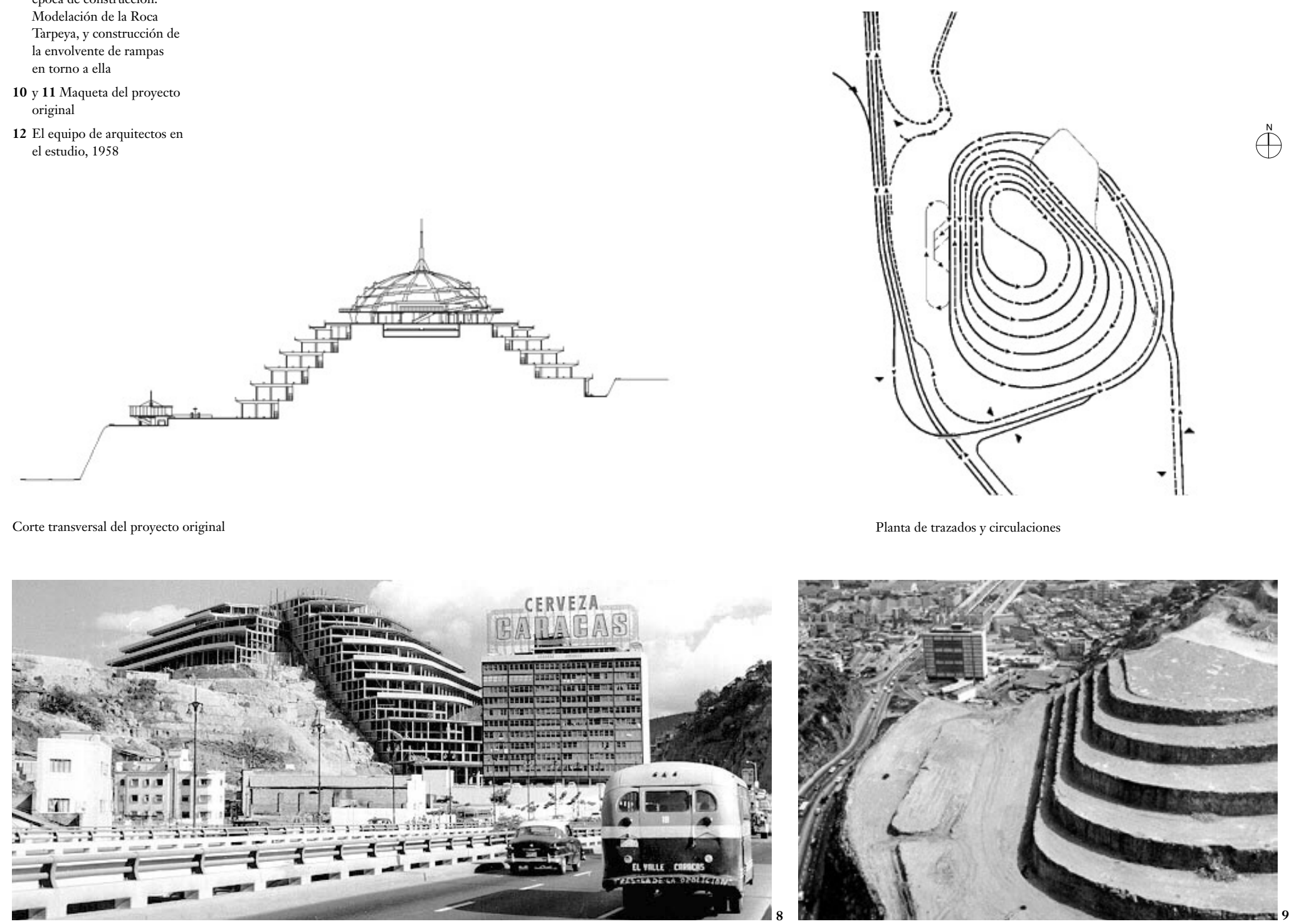

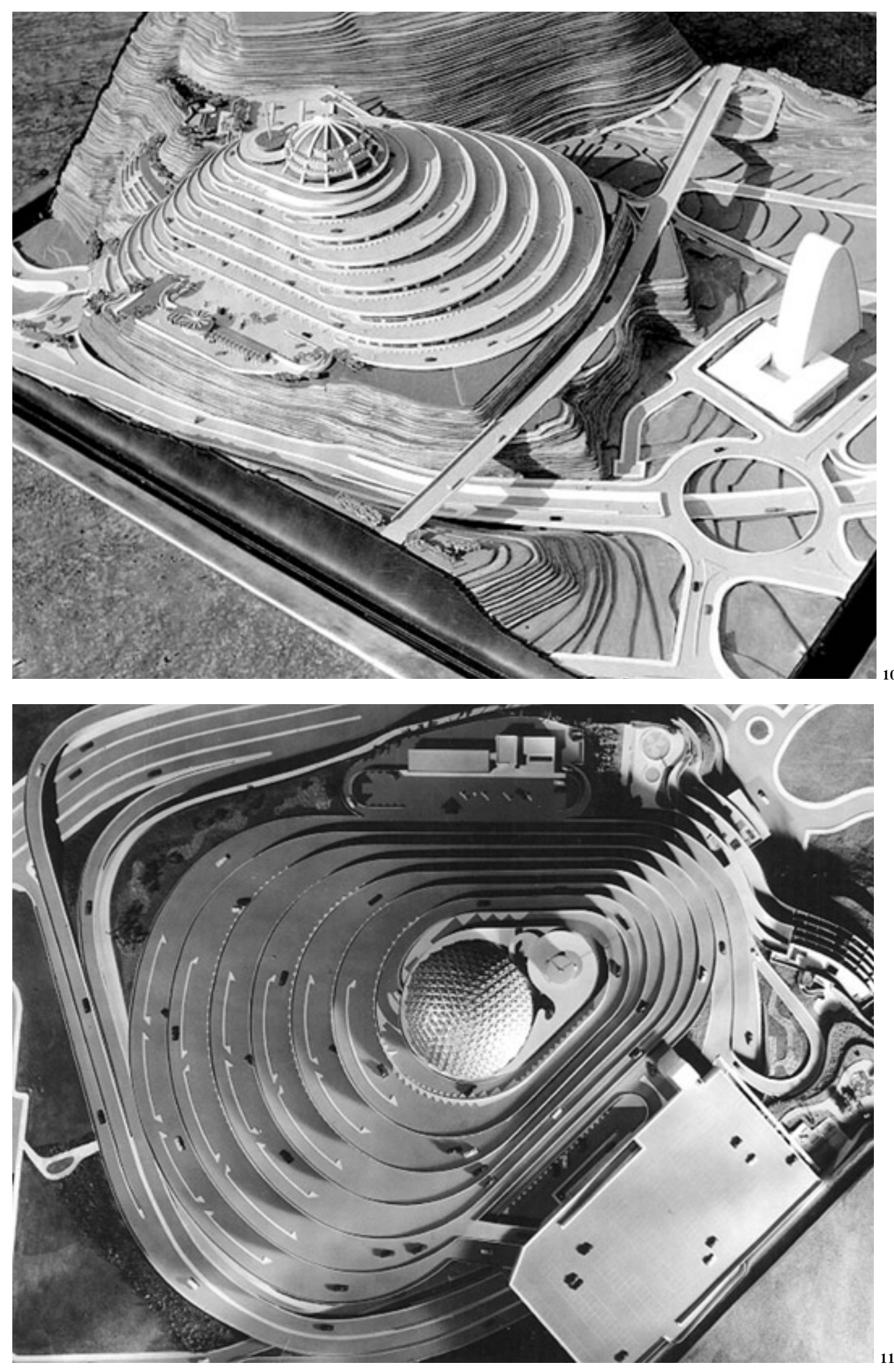

Automotriz compuesto de una bomba de gasolina, túnel de lavado automático, taller mecánico y local de venta de autos. En la cima del edificio, donde se ubica un centro de exposiciones, es donde se resuelve la articulación de la espiral de subida con la espiral de bajada, gracias a una curva en forma de "S", logrando así un tráfico en una sola dirección sin cruces.

Cabe mencionar que la construcción del Helicoide por factores de orden político se detuvo en 1961 cuando se terminaron los últimos trabajos en concreto $\operatorname{armado}^{7}$. Paradojalmente ese mismo año esta obra era exhibida en el Museo de Arte
Moderno de Nueva York en la exposición "Roads" alcanzando una notable proyección en el debate arquitectónico internacional.

Hoy, cuatro décadas después, aún constituye un desafío para la arquitectura latinoamericana, y en especial para la arquitectura en Venezuela, que en este período ha perdido reflexión crítica y capacidad de riesgo. ARQ

Más informaciones en Caracas: la ciudad moderna, CD-ROM. / Universidad Católica Andrés Bello $\mathrm{UCAB} /$ Centro de Investigaciones de la Comunicación CIC-UCAB / Consejo Nacional de Investigaciones Científicas y Tecnológicas CONICIT, Caracas.

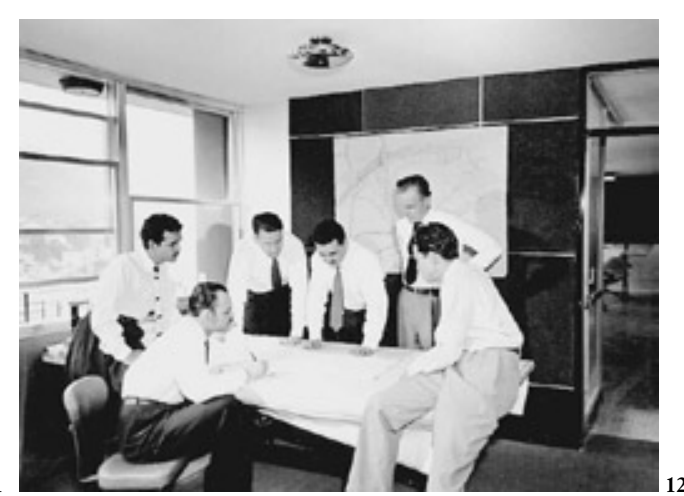

El Helicoide

Arquitectos Jorge Romero, Pedro Neuberser y Dirk Bornhorst Ubicación Roca Tarpeya, Avenida de las Fuerzas Armadas y Avenida Victoria, Caracas, Venezuela

Superficie terreno $101.940 \mathrm{~m}^{2}$, construida $77.748 \mathrm{~m}^{2}$

Kías y áreas verdes $29.192 \mathrm{~m}^{2}$

Área locales comerciales $46.715 \mathrm{~m}^{2}$

Área de Exposición e Industrias $8.445 \mathrm{~m}^{2}$

Recorrido total en vehículo $4 \mathrm{~km}$

Superficie de frente comercial $3 \mathrm{~km}$

Año construcción 1958-1961

Fotografías: Paolo Gasparini, y Centro de Investigaciones de la Comunicación de la UCAB, Caracas 